Keywords: cyclooxygenase inhibitors; aspirin; Barrett's esophagus; esophageal adenocarcinoma; neoplastic progression; chemoprevention; meta-analysis

\title{
Cyclooxygenase inhibitors use is associated with reduced risk of esophageal adenocarcinoma in patients with Barrett's esophagus: a meta-analysis
}

\author{
S Zhang ${ }^{1,2,6}$, X-O Zhang ${ }^{1,2,6}$, X-W Ding ${ }^{1,2}$, R-K Yang ${ }^{3}$, S-L Huang ${ }^{1}$, F Kastelein ${ }^{4}$, M Bruno ${ }^{4}$, X-J Yu ${ }^{5}$, D Zhou ${ }^{2}$ \\ and X-P Zou ${ }^{\star, 1,2}$ \\ ${ }^{1}$ Department of Gastroenterology, Drum Tower Hospital Affiliated to Medical School of Nanjing University, Nanjing 210008, \\ China; ${ }^{2}$ Medical School of Nanjing University, Nanjing 210008, China; ${ }^{3}$ Department of Intensive Care Medicine, University of \\ Tampere Medical School, Tampere 33014, Finland; ${ }^{4}$ Department of Gastroenterology and Hepatology, Erasmus University \\ Medical Center, 3015 CE Rotterdam, The Netherlands and ${ }^{5}$ Department of Epidemiology and Biostatistics, Public Health School, \\ Southeast University, Nanjing 210008, China
}

Background: Esophageal adenocarcinoma (EAC) has high mortality and is increasing in incidence. Barrett's esophagus (BE) increases the risk for EAC. Studies have reported inconsistent findings on the association between use of cyclooxygenase (COX) inhibitors and the risk of neoplastic progression in BE patients. Therefore, we performed a meta-analysis to investigate this association.

Methods: A meta-analysis was undertaken among a total of 9 observational studies using fixed- and random-effects models, comprising 5446 participants; 605 had EAC or high-grade dysplasia (HGD).

Results: Overall, COX inhibitors use was associated with a reduced risk of EAC/HGD among BE patients (relative risk (RR) $=0.64$, $95 \%$ confidence interval $(\mathrm{Cl})=0.53-0.77)$. Aspirin use also reduced the risk of $E A C / H G D(R R=0.63,95 \% \mathrm{Cl}=0.43-0.94)$, as well as non-aspirin COX inhibitors $(\mathrm{RR}=0.50,95 \% \mathrm{Cl}=0.32-0.78)$. The chemopreventive effect seemed to be independent of duration response.

Conclusions: Cyclooxygenase inhibitors use is associated with a reduced risk of developing EAC in patients with BE. Both low-dose aspirin and non-aspirin COX inhibitors are associated with a reduced risk of neoplasia. More well-designed randomised controlled trials are needed to increase our understanding of the chemopreventive effect of COX inhibitors.

The incidence of esophageal adenocarcinoma (EAC) has increased dramatically over the past decades (Bollschweiler et al, 2001; Vizcaino et al, 2002). With high mortality, EAC has become the most universal histological type of esophageal cancer in western countries (Polednak, 2003; Vaughan et al, 2005). Barrett's esophagus (BE), defined as a premalignant condition in which any extent of metaplastic columnar epithelium replaces the normal stratified squamous epithelium of the distal esophagus, has generally been regarded as the only established precursor lesion for EAC (Spechler et al, 2011). BE is a relatively common condition with an estimated prevalence of about $1-2 \%$ in the general population (Ronkainen et al, 2005), and $\sim 10-15 \%$ in patients 
undergoing endoscopy for gastroesophageal reflux disease (GERD) (Sharma and Sidorenko, 2005). In patients with non-dysplastic BE, the annual incidence rate of developing EAC is estimated to be around $0.33 \%$ (Desai et al, 2012). However, the time course and risk factors for the progression of $\mathrm{BE}$ to $\mathrm{EAC}$ remain largely unknown.

The increasing incidence of EAC and its poor prognosis have led to a search for methods to prevent the neoplastic progression of BE. Many studies, including three meta-analyses, have supported the potential of chemoprevention with cyclooxygenase (COX) inhibitors, including aspirin, non-selective non-steroidal anti-inflammatory drugs (nsNSAIDs), and selective COX-2 inhibitors, for esophageal cancer (Corley et al, 2003; Abnet et al, 2009; Sun and Yu, 2011). Corley et al demonstrated a protective association between COX inhibitors use and esophageal cancer (of both histological types) and provided evidence for a dose effect. Abnet et al found that COX inhibitors use was inversely associated with EAC in their meta-analysis. Moreover, Sun et al reported that COX inhibitors reduced the risk for esophageal squamous cell carcinoma. An important limitation of these studies is the absence of information on BE states in the patients. Thus COX inhibitors could exert their antitumour effect either by reducing the risk of BE patients progressing into EAC, or by reducing the risk of $\mathrm{BE}$. Since $\mathrm{BE}$ is the only known precancerous lesion for EAC, any cancer reducing effect for COX inhibitors should be best shown among BE patients. And chemoprevention for EAC would not be advocated on a population level. However, it could reasonably be considered in high-risk groups, such as patients with $\mathrm{BE}$.

Inhibition of the COX-2 enzyme is hypothesised to be one of the mechanisms by which COX inhibitors might exert their antitumour effects. Increased expression of COX-2 was observed in the early development of many tumours including EAC and was also found to be associated with malignant progression of $\mathrm{BE}$ along the metaplasia-dysplasia-adenocarcinoma sequence (Molina et al, 1999; Fosslien, 2000; Shirvani et al, 2000; Kandil et al, 2001; Morris et al, 2001; Spechler et al, 2011). Substantial experimental data also suggest that COX inhibitors might be effective chemopreventive agents for patients with BE. For example, COX inhibitors, both selective and non-selective, have been found to decrease the progression of EAC in animal models of GERD or BE (Buttar et al, 2002; Oyama et al, 2005; Kim et al, 2007). Rofecoxib was reported to reduce cell proliferation in biopsy specimens of Barrett's epithelium taken from patients (Kaur et al, 2002). Thus, we suggest that COX inhibitors might have an important role in preventing $\mathrm{BE}$ from developing into dysplasia or adenocarcinoma.

To date, only a few epidemiological studies with inconsistent results have been carried out in patients with $\mathrm{BE}$. A randomisedcontrolled trial (RCT) published in 2007 by Heath et al (2007) demonstrated that secondary chemoprevention with celecoxib did not reduce the risk of developing EAC in patients with BE. Although some meta-analyses on the chemopreventive effect of COX inhibitors in esophageal cancer with limitations have been performed (Corley et al, 2003; Abnet et al, 2009; Sun and Yu, 2011), no meta-analyses assessed the association between COX inhibitors use and progression to EAC in patients with BE. So, the protective effect of COX inhibitors on the neoplastic development in patients with $\mathrm{BE}$ has remained uncertain.

We therefore performed a meta-analysis of existing observational studies to investigate the association between COX inhibitors ingestion and the risk of neoplastic progression in patients with $\mathrm{BE}$, following the MOOSE guidelines (Stroup et al, 2000). We aim to give support to a more definitive answer on whether preventive use of COX inhibitors can reduce the risk of neoplastic progression in patients with $\mathrm{BE}$.

\section{MATERIALS AND METHODS}

Search strategy. We conducted a computer-assisted systematic search of MEDLINE, EMBASE, and Web of Science databases from their commencement to July 2013. We used similar search terms for MEDLINE and EMBASE (see Appendix A). Web of Science was searched mainly for abstracts of additional gastrointestinal/oncology society meetings. The language of publications was not restricted. We also reviewed the bibliographies of relevant articles to identify additional studies that might have been missed by the database searches.

Study selection. Two of the authors (ZS and DXW) independently screened titles and abstracts of the papers to identify studies that might meet the inclusion criteria and discard those that clearly did not. Full text of studies selected for further review was retrieved and evaluated. Studies were included if they met the following criteria: (1) evaluated exposure to any type of COX inhibitors; (2) the primary outcome was clearly defined as EAC or high-grade dysplasia (HGD); (3) patients included should be definitely diagnosed as having BE in the past or at present; (4) provided odds ratios (ORs), relative risks (RRs), or hazard ratios (HRs) with confidence intervals (CIs), or original data necessary to calculate the RR.

Data extraction. All data were extracted independently and crosschecked by three of the authors (ZS, ZXQ, and HSL) according to the inclusion criteria. Discrepancies were discussed and resolved by consensus. The following data were collected from each study: the first author, publication year, the country in which the study was performed, study design, medication type, information source for exposure measurement (for example, questionnaire or pharmacy database), number of participants, OR/RR/HR with corresponding $95 \%$ CI for each category, and confounders included in each adjusted estimate (Tables 1 and 2). Also, the inclusion criteria and potential types of bias of each study were provided in Supplementary Table 1. We tried to extract the risk estimates (OR/RR/HR) from the Results section with and without adjustment for multiple confounders. However, in some studies the authors did not provide the unadjusted estimates but the primary data (number of cases and controls) necessary to calculate them. For these studies, the unadjusted RRs were calculated using the Pearson Chi-Square test with SPSS Statistics 17 (IBM Corporation, Armonk, NY, USA).

Statistical analysis. Stata Statistical Software was used for all the analyses (version 12.0; Stata Corporation, College Station, TX, USA). The measure of estimated effect of interest was the RR with 95\% CI. Because the risk of EAC in patients with BE is relatively low, the RR mathematically approximates the OR in case-control studies and the HR in cohort studies. We therefore reported all results as the RR for simplicity, and summary RR estimates were calculated using $\mathrm{RR}, \mathrm{OR}$, or $\mathrm{HR}$ reported in each study (Greenland, 1987).

The $Q$ and $I^{2}$ statistics were used to test statistical heterogeneity among studies (Higgins and Thompson, 2002). If the results were homogeneous, then the fixed-effects model with Mantel-Haenszel method should be used. Otherwise, the random-effects model with DerSimonian and Laird method should be used (DerSimonian and Laird, 1986; Greenland, 1994; Poole and Greenland, 1999). In this meta-analysis, we calculated summary RR estimates using both the fixed- and the random-effects model, and compared them to evaluate for potential heterogeneity.

Stratified analyses were conducted for several factors including study design, medication type (aspirin and non-aspirin COX inhibitors) and duration of COX inhibitors use to examine potential interactions. 
Table 1. Study characteristics

\begin{tabular}{|c|c|c|c|c|c|c|c|}
\hline $\begin{array}{l}\text { Author/country/year of } \\
\text { publication }\end{array}$ & $\begin{array}{l}\text { No. of EAC/HGD } \\
\text { cases/No. of } \\
\text { participants }\end{array}$ & $\begin{array}{c}\text { Definition } \\
\text { of exposure } \\
\text { to } \\
\text { medications }\end{array}$ & Design & Exposure & $\begin{array}{l}\text { Age at } \\
\text { baseline, } \\
\text { years, } \\
\text { mean or } \\
\text { range }\end{array}$ & $\begin{array}{l}\text { Exposure } \\
\text { source }^{a}\end{array}$ & $\begin{array}{l}\text { Confounders } \\
\text { included in } \\
\text { adjusted } \\
\text { estimates }\end{array}$ \\
\hline Tsibouris/UK/2004 & $114 / 496$ & $\geqslant 2$ years & Case-control/Retrospective & $\begin{array}{c}\text { COX } \\
\text { inhibitors }\end{array}$ & $\begin{array}{l}73(\mathrm{EAC}) / \\
68.4(\mathrm{BE})\end{array}$ & Database & $a, b, c, d, e, f, i$ \\
\hline E Bani-Hani/UK/2005 & $44 / 597$ & - & Case-control/Retrospective & $\begin{array}{c}\text { COX } \\
\text { inhibitors }\end{array}$ & 63.4 & Database & $a, b, c, d, e, l, m$ \\
\hline Vaughan/USA/2005 & $37 / 350$ & $\begin{array}{c}\text { At least once a } \\
\text { week } \geqslant 6 \\
\text { months }\end{array}$ & Cohort/Prospective & \begin{tabular}{c|c} 
COX \\
inhibitors
\end{tabular} & $>30$ & Questionnaire & $a, b, d, g, l$ \\
\hline Gatenby/UK/2009 & $\begin{array}{c}20(\text { EAC)/30 } \\
(\mathrm{HGD} / \mathrm{EAC}) / 736\end{array}$ & - & Cohort/Retrospective & Aspirin & 64.5 & Database & $a, b, h$ \\
\hline Nguyen/USA/2009 & $33(\mathrm{HGD} / \mathrm{EAC}) / 344$ & $\begin{array}{c}\geqslant 1 \\
\text { prescription }\end{array}$ & Cohort/Retrospective & $\begin{array}{c}\text { COX } \\
\text { inhibitors }\end{array}$ & 60.7 & Database & $a, b, e$ \\
\hline Gaddam/USA/2010 & 185 (HGD/EAC)/1496 & - & Cohort/Prospective & $\begin{array}{c}\text { COX } \\
\text { inhibitors }\end{array}$ & 62.8 & - & $a, d, e, g$ \\
\hline Nguyen/USA/2010 & $116 / 812$ & $\begin{array}{c}\geqslant 1 \\
\text { prescription }\end{array}$ & Nested case-control/Retrospective & $\begin{array}{c}\text { COX } \\
\text { inhibitors }\end{array}$ & 65.0 & Database & $\mathrm{j}, \mathrm{k}$ \\
\hline Kastelein/The Netherlands/2011 & 38 (HGD/EAC)/570 & $\begin{array}{c}\text { nsNSAIDs } \\
>325 \mathrm{mg} \text { per } \\
\text { day, aspirin } \\
<100 \mathrm{mg} \text { per } \\
\text { day }\end{array}$ & Cohort/Prospective & $\begin{array}{c}\text { COX } \\
\text { inhibitors }\end{array}$ & 60.4 & Database & $a, b, e, h, k$ \\
\hline Kantor/USA/2012 & $45 / 395$ & - & Cohort/Prospective & $\begin{array}{c}\text { COX } \\
\text { inhibitors } \\
\end{array}$ & $>30$ & Questionnaire & $a, b, d, k$ \\
\hline $\begin{array}{l}\text { Abbreviations: } B E=\text { Barrett's esoph } \\
\text { a, age; b, sex; c, alcohol abuse; } d \text {, } \\
\text { l, education level; m, esophagitis, b } \\
\text { a } \text { Source of exposure data. } \\
\text { b We did not obtain this study by Va } \\
\text { (aspirin vs non-aspirin COX inhibitor }\end{array}$ & $\begin{array}{l}\text { yus; } \mathrm{BMI}=\text { body mass ind } \\
\text { oking history; e, BE lengt } \\
\text { ign esophageal stricture, } \\
\text { ghan in the overall meta-a } \\
\text { and duration response (s }\end{array}$ & $\begin{array}{l}\text { ex; COX }=\text { cycloo } \\
h ; f, \text { duration of re } \\
\text { ulcers or H. pylor } \\
\text { nalysis for COX in } \\
\text { horter duration vs }\end{array}$ & $\begin{array}{l}\text { xygenase; } E A C=\text { esophageal adenocar } \\
\text { flux; g, BMI; } h \text {, baseline histology; i, hia } \\
\text { infection. } \\
\text { hibitors use, but we extracted data from } \\
\text { longer duration). }\end{array}$ & $\begin{array}{l}\text { cinoma; HGD = } \\
\text { tus hernia; j, ra } \\
\text { this study for }\end{array}$ & $\begin{array}{l}\text { high-grade } d \\
e ; k \text {, use of o } \\
\text { ubgroup met }\end{array}$ & $\begin{array}{l}\text { splasia; PPI = pro } \\
\text { ner medications, } \\
\text {-analysis consider }\end{array}$ & $\begin{array}{l}\text { ton pump inhibitor. } \\
\text { ng medication type }\end{array}$ \\
\hline
\end{tabular}

Table 2. Estimates of EAC/HGD (RR/OR/HR) in patients with BE for any COX inhibitors use in each study

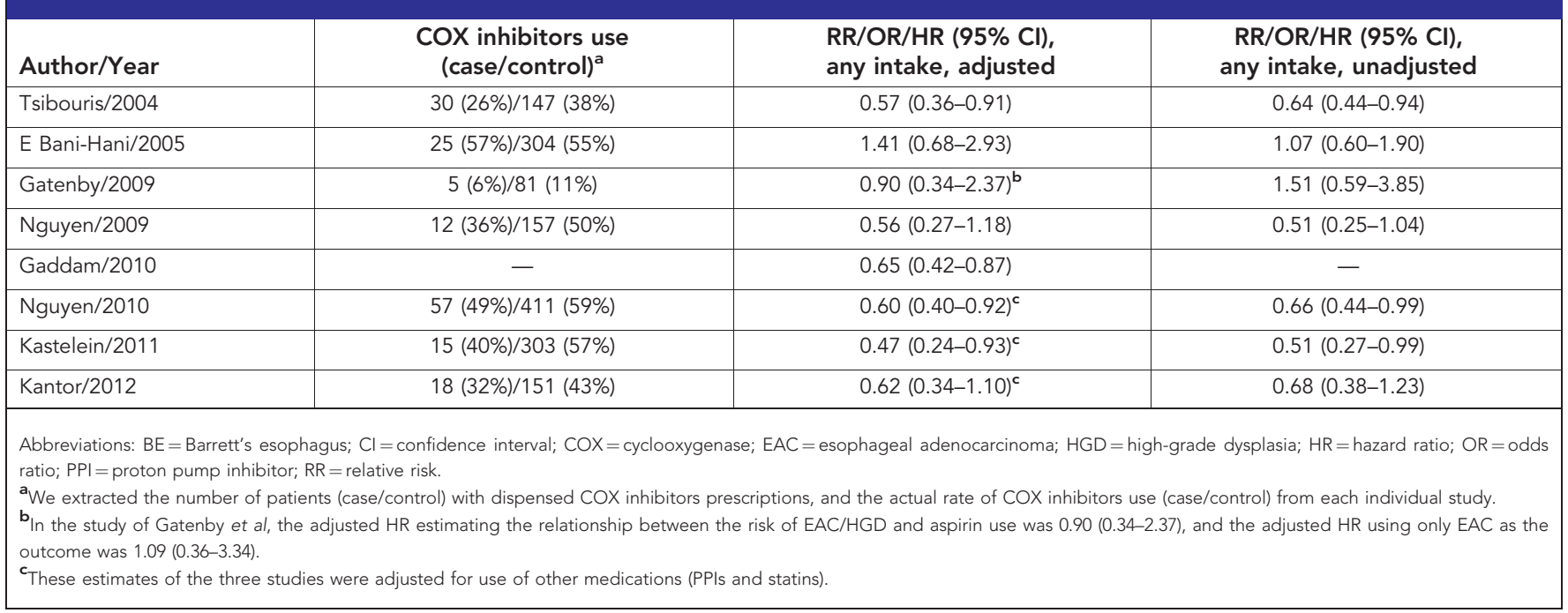

Qualitative assessment. So far, no scale has been universally adopted for measuring quality of observational studies. Two of the authors (ZS and ZXQ) assessed study quality independently using the 9-star Newcastle-Ottawa Scale (NOS) (Wells et al, 2013) (see Appendix B).
Assessment of heterogeneity. For the $Q$ statistic, heterogeneity was considered as statistically significant if $P \leqslant 0.1$ (rather than $P<0.05) . I^{2}$ is the proportion of total variation contributed by between-study variation (Higgins and Thompson, 2002), and values of $25 \%, 50 \%$, and $75 \%$ have been regarded as 
representing low, moderate, and high heterogeneity, respectively (Higgins et al, 2003).

We carried out several methods to avoid potential heterogeneity as much as possible and obtain confident results. First, baseline differences between groups and the impossibility to guarantee randomisation could influence the results of observational studies. So, we used each author's reported (or calculated) RR/OR/HR with and without adjustment for variable confounders to calculate summary estimated RRs. Second, we performed a sensitivity analysis by separately omitting one study at a time to assess whether the pooled estimate has changed statistically significantly compared with the results containing all the studies. Third, a subgroup analysis was carried out by stratifying analyses with several factors including study design (cohort $v s$ case-control, retrospective $v s$ prospective), medication type (aspirin $v s$ nonaspirin COX inhibitors), and duration of COX inhibitors use (shorter duration $v s$ longer duration) (Kleinbaum et al, 1982; Chalmers et al, 1983; Gerbarg and Horwitz, 1988; Schulz et al, 1994, 1995; Jadad et al, 1996; Imperiale and Birgisson, 1997).

Publication bias. Qualitative and quantitative methods were used to assess the publication bias. We visually inspected the funnel plot, and used Begg's test to calculate a correlation coefficient between the log RRs and their standard errors (Begg and Mazumdar, 1994). Publication bias was considered to be present if $P \leqslant 0.1$ (Kendall and Gibbons, 1990).

\section{RESULTS}

Study characteristics. A total of 145 potential studies were identified with the MEDLINE search. In addition, the EMBASE search yielded 579 and the Web of Science search 316 potentially relevant articles. After reviewing the titles, abstracts, and some of the full text of the studies, we selected 11 publications that met the initial inclusion criteria (Tsibouris et al, 2004; Bani-Hani et al, 2005; Vaughan et al, 2005; de Jonge et al, 2006; Gatenby et al, 2009; Nguyen et al, 2009, 2010; Gaddam et al, 2010; Kastelein et al, 2011; Beales et al, 2012; Kantor et al, 2012). The studies excluded were reduplicative, review articles, animal experiments, or those which did not report on the subject of interest. Then all the 11 papers were carefully read, and 2 of them were further excluded. In the two case-control studies, the authors compared patients with BE to patients with EAC who did not have a clear diagnosis of BE, which could lead to loss of validity of the results (de Jonge et al, 2006; Beales et al, 2012). We did not obtain any additional relevant study through manual review of the bibliographies (Figure 1).

We analysed data from the remaining nine articles, among which one was an abstract (Gaddam et al, 2010). We included 2 case-control studies, 6 cohort studies, and 1 case-control study nested in a well-defined cohort, comprising 5446 participants, of whom 605 were diagnosed with EAC or HGD. Because of their characteristics, the nested case-control study was included in the cohort study group. Among them two articles were published by the same authors with the same population (the Seattle Barrett's esophagus project) (Vaughan et al, 2005; Kantor et al, 2012). We chose the more recent one published in 2012 instead of the other in 2005 when performing the meta-analysis for overall COX inhibitors use. Nevertheless, the study in 2005 provided risk estimate for medication type (aspirin and non-aspirin COX inhibitors) and duration response, while the more recent one did not. Consequently, eight studies were included in the overall metaanalysis for COX inhibitors use. Data from the article published in 2005 were only used for the subgroup analysis considering medication type and duration response (Vaughan et al, 2005). All the meta-analysis results were shown in Table 4 .

Quality of the included studies. The studies were judged to be 6, 7 , 8, or 9 points on the 9-star Newcastle-Ottawa Scale. Seven studies were considered to be of high quality ( $>7$ points). The details of the quality assessment for each study are shown in Supplementary Table 2.

Neoplastic progression (all types of COX inhibitors). Altogether a smaller proportion of cases were prescribed COX inhibitors compared with controls $(38.6 \%$ vs $39.7 \%)$. Patients with any exposure to any type of COX inhibitors had a significant risk reduction in developing $\mathrm{EAC} / \mathrm{HGD}$ (adjusted $\mathrm{RR}=0.64,95 \%$ $\left.\mathrm{CI}=0.53-0.77, P_{\text {homogeneity }}=0.512\right)$ in an overall analysis using estimates adjusted for potential confounders in each study (Figure 2A). The unadjusted RR was also calculated (unadjusted $\left.\mathrm{RR}=0.70,95 \% \mathrm{CI}=0.56-0.86, P_{\text {homogeneity }}=0.357\right)$.

Then, we omitted one study at a time to see whether the magnitude, statistical significance, or heterogeneity had substantially changed. However, no study markedly influenced the result of summary estimates.
Potentially relevant articles identified through MEDLINE ( $n=145)$, EMBASE $(n=579)$, and the Web of Science $(n=316)$ search updated to July $2013(n=1040)$
1029 articles excluded based on titles, abstracts and some of the full texts. Studies excluded were reduplicative, review articles, animal experiments, or they didn't report on the subject of interest.

$$
\text { Full-text articles obtained for detailed }
$$
examination $(n=11)$

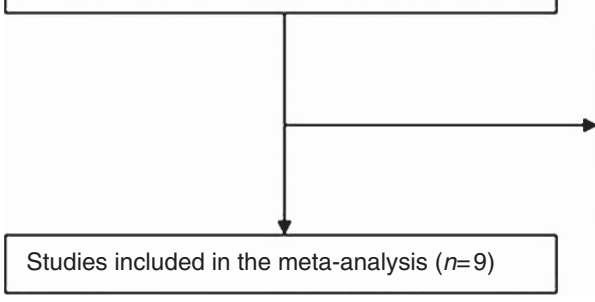

Studies excluded after full text review $(n=2)$

-The authors were not able to make sure all the esophageal cancers had a history of $\mathrm{BE}$

Figure 1. Flow diagram of study identification and selection. 
A

\begin{tabular}{|c|c|c|}
\hline Study ID & $\mathrm{RR}(95 \% \mathrm{Cl})$ & $\%$ Weight \\
\hline Tsibouris 2004 & $0.57(0.36,0.91)$ & 16.72 \\
\hline E Bani-Hani 2005 & $1.41(0.68,2.93)$ & 6.74 \\
\hline Gatenby 2009 & $0.90(0.34,2.37)$ & 3.81 \\
\hline Nguyen 2009 & $0.56(0.27,1.18)$ & 6.61 \\
\hline Gaddam 2010 & $0.65(0.42,0.87)$ & 27.12 \\
\hline Nguyen 2010 & $0.60(0.40,0.92)$ & 20.73 \\
\hline Kastelein 2011 & $0.47(0.24,0.93)$ & 7.84 \\
\hline Kantor 2012 & $0.62(0.34,1.10)$ & 10.43 \\
\hline Overall (I-squared $=0.0 \%, P=0.512)$ & $0.64(0.53,0.77)$ & 100.00 \\
\hline Note: Weights are from random-effects analysis & & \\
\hline $\begin{array}{c}1 \\
0.5\end{array}$ & ${ }_{1.5}^{1}$ & \\
\hline
\end{tabular}

B

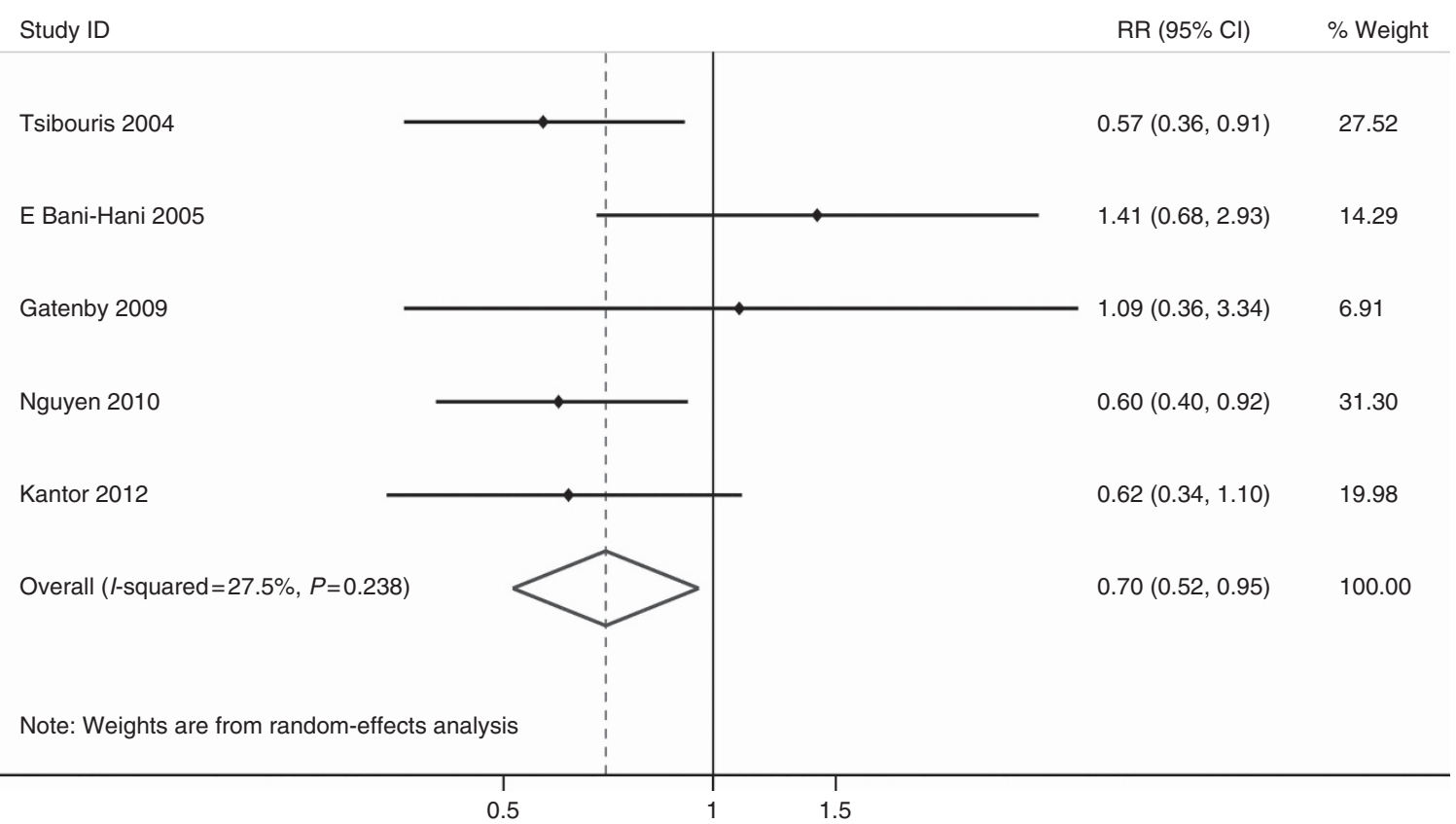

Figure 2. (A) Forest plot assessing overall COX inhibitors use and the risk of EAC/HGD in patients with BE. (B). Forest plot assessing overall COX inhibitors use and the risk of EAC only in patients with BE.

Five of the included studies used only EAC as the outcome (see Tables 1 and 2). So, we performed a subgroup meta-analysis among these studies and showed a significant risk reduction in developing EAC (adjusted $\mathrm{RR}=0.70, \quad 95 \% \mathrm{CI}=0.52-0.95$, $\left.P_{\text {homogeneity }}=0.238\right)($ Figure $2 \mathrm{~B})$.

Study design. The adjusted estimates for cohort studies (adjusted $\left.\mathrm{RR}=0.61,95 \% \mathrm{CI}=0.49-0.76, P_{\text {homogeneity }}=0.929\right)$ were somewhat different from the adjusted estimates for case-control studies (adjusted $\mathrm{RR}=0.86, \quad 95 \% \mathrm{CI}=0.35-2.07, \quad P_{\text {homogeneity }}=0.04$ ) which was not statistically significant. (Figure 3 ).

Among the six cohort studies, three of them were retrospective and the other three were prospective. So, we performed the sensitivity analysis to investigate the difference between retrospective cohort studies (adjusted $\mathrm{RR}=0.62, \quad 95 \%$ $\left.\mathrm{CI}=0.44-0.87, P_{\text {homogeneity }}=0.718\right)$ and prospective cohort studies (adjusted $\mathrm{RR}=0.61,95 \% \mathrm{CI}=0.46-0.81, \quad P_{\text {homogeneity }}=0.709$ ) (see Supplementary Figure 1).

Duration response. To search for a duration response, we performed a subgroup analysis among those studies providing risk estimates for duration effect (Table 3).

Because the definition of longer duration in each study varied substantially ( 2 months, 1 year, 2 years, 3 years, and 5 years), we defined 1 year, 2 years, and 3 years as longer duration, and performed subgroup meta-analysis separately (see Supplementary Figure 2). Cyclooxygenase inhibitors use for $>1$ year was associated with a significantly lower risk of neoplastic progression 


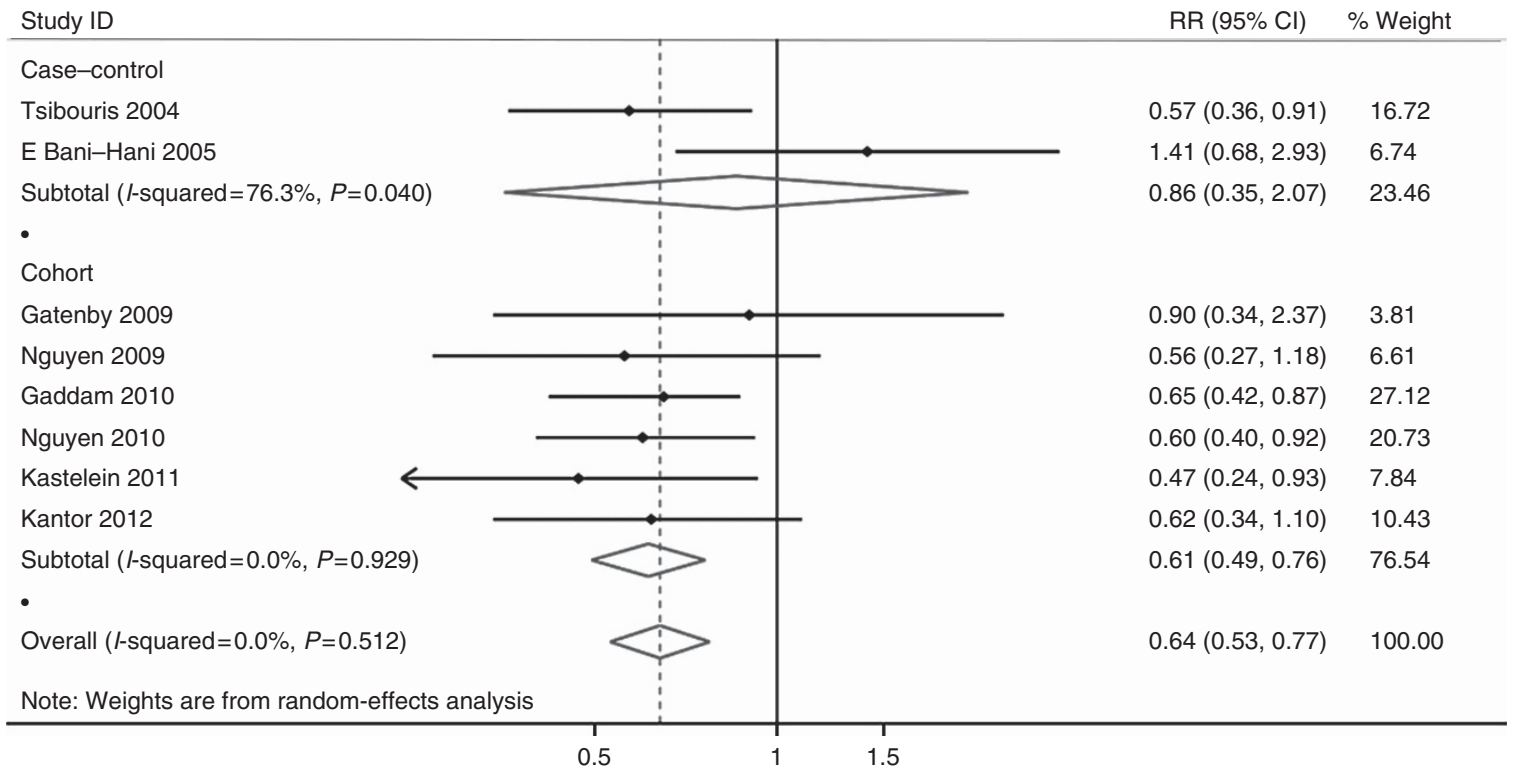

Figure 3. Forest plot of COX inhibitors intake and EAC/HGD risk in patients with BE considering study design (case-control vs cohort).

\begin{tabular}{|c|c|c|c|c|}
\hline Author/Year & $\begin{array}{c}\text { Case/Control (shorter } \\
\text { duration) }\end{array}$ & $\begin{array}{c}\text { RR/OR/HR }(95 \% \mathrm{Cl}) \text {, shorter } \\
\text { duration, adjusted }\end{array}$ & $\begin{array}{c}\text { Case/Control (longer } \\
\text { duration) }\end{array}$ & $\begin{array}{l}\mathrm{RR} / \mathrm{OR} / \mathrm{HR}(95 \% \mathrm{Cl}) \text {, longer } \\
\text { duration, adjusted }\end{array}$ \\
\hline Tsibouris/2004 & - & - & $14 / 88$ & $0.51(0.22-1.19)$ (daily use $>2$ years) \\
\hline Vaughan/2005 & - & $0.37(0.15-0.91)(<5$ years $)$ & - & $0.55(0.25-1.21)(>5$ years $)$ \\
\hline Nguyen/2009 & $6 / 80$ & 0.49 (0.20-1.22) (<36 months) & $6 / 59$ & 0.53 (0.21-1.32) (> 36 months) \\
\hline Nguyen/2010 & $43 / 295$ & 0.70 (0.46-1.07) (<12 months) & $14 / 116$ & 0.55 (0.29-1.06) (>12 months) \\
\hline Kastelein/2011 & $10 / 155$ & 0.58 (0.27-1.25) (<2 months) & $5 / 148$ & 0.32 (0.12-0.86) (>2 months) \\
\hline
\end{tabular}

(adjusted $\mathrm{RR}=0.54,95 \% \mathrm{CI}=0.36-0.79, \mathrm{P}_{\text {homogeneity }}=0.999$ ), as compared with use for $<1$ year (adjusted $\mathrm{RR}=0.67$, 95\% $\left.\mathrm{CI}=0.46-0.97, P_{\text {homogeneity }}=0.674\right)$. And longer duration of COX inhibitors ( $>2$ years) was also associated with greater risk reduction (adjusted $\mathrm{RR}=0.53, \quad 95 \% \quad \mathrm{CI}=0.33-0.87$, $\left.P_{\text {homogeneity }}=0.992\right)$ than shorter duration $(<2$ years $)$ (adjusted $\left.\mathrm{RR}=0.67,95 \% \mathrm{CI}=0.46-0.97, P_{\text {homogeneity }}=0.674\right)$. Moreover, use for $>3$ years was associated with a lower risk of EAC/HGD (adjusted $\mathrm{RR}=0.54,95 \% \mathrm{CI}=0.30-0.99, P_{\text {homogeneity }}=0.952$ ) as compared with use for $<3$ years (adjusted $\mathrm{RR}=0.64,95 \%$ $\left.\mathrm{CI}=0.46-0.90, P_{\text {homogeneity }}=0.751\right)$. However, none of the differences between the three groups were statistically significant (Table 4).

Medication type. Although the study by Vaughan et al (2005) was excluded from the overall analysis for COX inhibitors use, we included it in the subgroup analysis for medication type. We extracted the risk estimates for aspirin and non-aspirin COX inhibitors use from relevant studies.

Altogether four studies provided aspirin estimates adjusted for potential confounders (Supplementary Table 3) (Tsibouris et al, 2004; Vaughan et al, 2005; Gatenby et al, 2009; Kastelein et al, 2011). Any exposure to aspirin was associated with a reduced risk of neoplastic progression (adjusted $\mathrm{RR}=0.63,95 \% \mathrm{CI}=0.43-0.94$, $\left.P_{\text {homogeneity }}=0.642\right)$. (Figure 4$)$.

Only three studies offered the adjusted estimate for non-aspirin COX inhibitors (Tsibouris et al, 2004; Vaughan et al, 2005; Kastelein et al, 2011). Patients with any exposure to any type of non-aspirin COX inhibitors also had a significant reduction in risk of $\mathrm{EAC} / \mathrm{HGD}$ (adjusted $\mathrm{RR}=0.50,95 \% \mathrm{CI}=0.32-0.78$, $\left.P_{\text {homogeneity }}=0.492\right)$ (Figure 4$)$.

Concomitant use of other medications. To explore the interactive effect of concomitant use of other putative chemopreventive medications as proton pump inhibitors (PPIs) and statins, we limited analysis to studies that adjusted for use of these additional medications (Nguyen et al, 2010; Kastelein et al, 2011; Kantor et al, 2012), and compared results with those that did not adjust (Tsibouris et al, 2004; Bani-Hani et al, 2005; Gatenby et al, 2009; Nguyen et al, 2009; Gaddam et al, 2010). The results showed a $42 \%$ reduction (adjusted $\mathrm{RR}=0.58, \quad 95 \% \quad \mathrm{CI}=0.43-0.78$, $\left.\mathrm{P}_{\text {homogeneity }}=0.801\right)$ for those adjusting for PPIs/statins, which was higher than those that did not adjust $(R R=0.70,95 \%$ $\left.\mathrm{CI}=0.53-0.93, P_{\text {homogeneity }}=0.285\right)$, although this difference was not statistically significant $\left(P_{\text {significance }}=0.38\right)$.

Over-the-counter medication use. Cyclooxygenase inhibitors are widely available over the counter and many studies have shown that the majority of use of these drugs is not prescribed. So, we wonder whether over-the-counter medication use will influence the overall results. In some of the included studies, information on medication use was collected prospectively, and patients also filled out a questionnaire on their use of over-the-counter medication. Besides, all information on medication use was crosschecked using pharmacy records (Kastelein et al, 2011; Kantor et al, 2012). In some other studies, the information on medication use was 
Table 4. Meta-analysis results

\begin{tabular}{|c|c|c|c|c|c|c|}
\hline Type of study & $\begin{array}{l}\text { No. of studies } \\
\text { (patients) }\end{array}$ & $\begin{array}{c}\mathrm{RR}(95 \% \mathrm{Cl}) \text { random } \\
\text { effects }\end{array}$ & $\begin{array}{c}\mathrm{RR}(95 \% \mathrm{Cl}) \text { fixed } \\
\text { effects }\end{array}$ & $P_{\text {heterogeneity }}$ & $\begin{array}{l}l_{\text {heterogeneity }}^{2} \\
(\%)\end{array}$ & $\begin{array}{c}P_{\text {significance }} \\
\text { between } \\
\text { groups }\end{array}$ \\
\hline All studies (adjusted) & $8 / 5446$ & $0.64(0.53-0.77)$ & $0.64(0.53-0.77)$ & 0.51 & 0 & \\
\hline All studies (EAC only) & $5 / 3036$ & $0.70(0.52-0.95)$ & $0.70(0.52-0.95)$ & 0.24 & 28 & \\
\hline All studies (unadjusted) & $7 / 3950$ & $0.70(0.56-0.86)$ & $0.69(0.57-0.85)$ & 0.36 & 7 & \\
\hline \multicolumn{7}{|l|}{ Study design } \\
\hline $\begin{array}{l}\text { Cohort studies } \\
\text { Case-control studies }\end{array}$ & $\begin{array}{l}6 / 4353 \\
2 / 1093\end{array}$ & $\begin{array}{l}0.61(0.49-0.76) \\
0.86(0.35-2.07)\end{array}$ & $\begin{array}{l}0.61(0.49-0.76) \\
0.74(0.50-1.09)\end{array}$ & $\begin{array}{l}0.93 \\
0.04\end{array}$ & $\begin{array}{r}0 \\
76\end{array}$ & 0.41 \\
\hline \multicolumn{7}{|c|}{ Study design in cohort studies } \\
\hline $\begin{array}{l}\text { Retrospective } \\
\text { Prospective }\end{array}$ & $\begin{array}{l}3 / 1892 \\
3 / 2461\end{array}$ & $\begin{array}{l}0.62(0.44-0.87) \\
0.61(0.46-0.81)\end{array}$ & $\begin{array}{l}0.62(0.44-0.87) \\
0.61(0.46-0.81)\end{array}$ & $\begin{array}{l}0.72 \\
0.71\end{array}$ & $\begin{array}{l}0 \\
0\end{array}$ & 0.92 \\
\hline \multicolumn{7}{|l|}{ Medication type } \\
\hline $\begin{array}{l}\text { Aspirin } \\
\text { Non-aspirin COX inhibitors }\end{array}$ & $\begin{array}{l}4 / 2152 \\
3 / 1416\end{array}$ & $\begin{array}{l}0.63(0.43-0.94) \\
0.50(0.32-0.78)\end{array}$ & $\begin{array}{l}0.63(0.43-0.94) \\
0.50(0.32-0.78)\end{array}$ & $\begin{array}{l}0.64 \\
0.49\end{array}$ & $\begin{array}{l}0 \\
0\end{array}$ & 0.44 \\
\hline \multicolumn{7}{|l|}{ Duration response } \\
\hline $\begin{array}{l}\text { Longer duration ( }>1 \text { year) } \\
\text { Shorter duration ( }<1 \text { year) } \\
\text { Longer duration ( }>2 \text { years) } \\
\text { Shorter duration ( }<2 \text { years) } \\
\text { Longer duration ( }>3 \text { years) } \\
\text { Shorter duration ( }<3 \text { years) }\end{array}$ & $\begin{array}{l}4 / 2002 \\
2 / 1382 \\
3 / 1190 \\
2 / 1382 \\
2 / 694 \\
3 / 1726 \\
\end{array}$ & $\begin{array}{l}0.54(0.36-0.79) \\
0.67(0.46-0.97) \\
0.53(0.33-0.87) \\
0.67(0.46-0.97) \\
0.54(0.30-0.99) \\
0.64(0.46-0.90)\end{array}$ & $\begin{array}{l}0.54(0.36-0.79) \\
0.67(0.46-0.97) \\
0.53(0.33-0.87) \\
0.67(0.46-0.97) \\
0.54(0.30-0.99) \\
0.64(0.46-0.90)\end{array}$ & $\begin{array}{l}1.00 \\
0.67 \\
0.99 \\
0.67 \\
0.95 \\
0.75 \\
\end{array}$ & $\begin{array}{l}0 \\
0 \\
0 \\
0 \\
0 \\
0\end{array}$ & $\begin{array}{l}0.42 \\
0.46 \\
0.63\end{array}$ \\
\hline
\end{tabular}

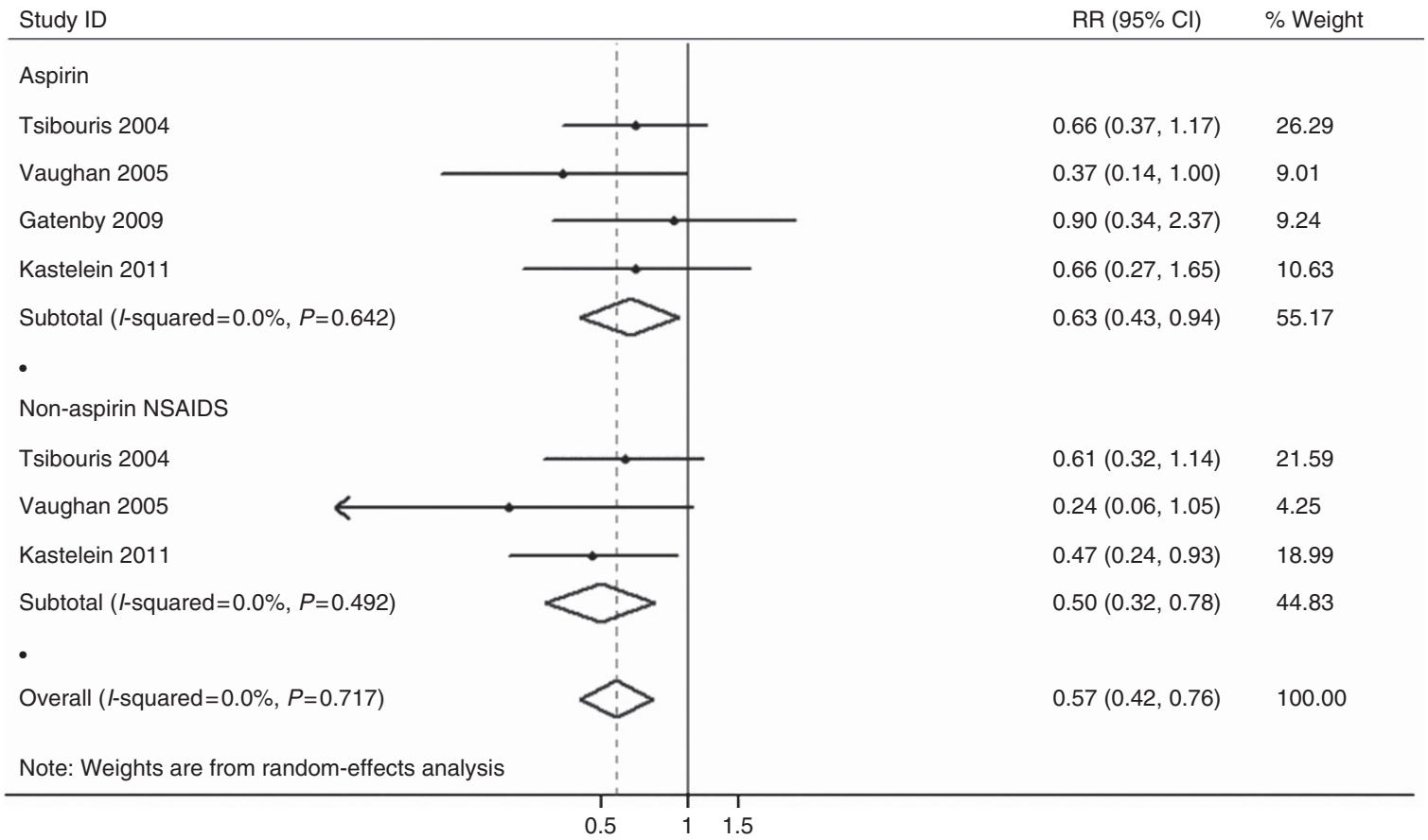

Figure 4. Forest plot of the risk of EAC/HGD associated with COX inhibitors use, organised separately by medication type (aspirin vs non-aspirin COX inhibitors).

collected retrospectively through questionnaires, including overthe-counter medication use (Tsibouris et al, 2004; Bani-Hani et al, 2005). Nguyen et al (2010) thought that patients with higher socio-economic status might be less likely to receive COX inhibitors prescription at the Veterans Affairs pharmacy. Consequently, their multivariate analysis adjusted for the patients' 
social-economic status. Nevertheless, the other included studies failed to address this problem. So, we performed a meta-analysis among the five studies including over-the counter medication use, and still found a significant risk reduction for COX inhibitors $\left(\mathrm{RR}=0.64,95 \% \mathrm{CI}=0.48-0.86, P_{\text {homogeneity }}=0.229\right)$, indicating that over-the-counter medication use might not affect the overall results.

Publication bias. As the number of the studies included in the analysis was small, visual inspection of funnel plots did not demonstrate convincing patterns. Using Begg's test to calculate a correlation coefficient between log RRs and their standard errors, we found there was no evidence of publication bias for overall summary estimates of COX inhibitors use $(P=0.902)$. Considering medication type, there was no obvious evidence of publication bias for aspirin or non-aspirin COX inhibitors use $(P=0.734$ for aspirin, $P=0.296$ for non-aspirin COX inhibitors).

\section{DISCUSSION}

In this meta-analysis, which pooled several large observational studies, a significant negative association was found between COX inhibitors use and the risk of neoplastic progression in patients with $\mathrm{BE}$ with an overall risk reduction of $36 \%$. A significant risk reduction of $30 \%$ was also found for EAC development.

We observed an obvious risk reduction in cohort studies $(39 \%$ reduction), while no significant risk reduction was observed in case-control studies, possibly due to recall bias and registration bias. And the number of case-control studies involved was too small to yield a convincing result. We also carried out a sensitivity analysis among the cohort studies comparing the risk estimates between retrospective (38\% reduction) and prospective cohort studies (39\% reduction), indicating that study design in terms of cohort studies did not affect the final results.

We also tried to explore whether there was a duration-response effect for COX inhibitors use. The classification for longer duration varied among the five studies from 2 months to 5 years. And the study of Tsibouris et al did not provide risk estimate for shorter duration ( $<2$ years). So, we defined longer duration as 1 year, 2 years, and 3 years, respectively, and carried out separate subgroup meta-analysis. We did not find any significant difference for risk reduction between longer duration and shorter duration, suggesting that use of COX inhibitors might be independent of duration response. In individual studies, Kastelein et al reported that NSAIDs use for $>2$ months was associated with a significant trend towards a lower risk of neoplastic development than NSAIDs use for 2 months or less, and Nguyen et al demonstrated that filled COX inhibitors prescriptions for at least 12 months had a nonsignificant greater reduction in EAC risk than those with $<12$ months' prescriptions. Nevertheless, in another study of Nguyen et al (2009), COX inhibitors use for $>3$ years indicated a lower risk reduction than COX inhibitors use for $<3$ years. And Vaughan et al also showed lower protective effect of COX inhibitors use for $>5$ years compared with COX inhibitors use for $<5$ years. With methodological limitations of meta-analysis and the varying definitions for duration response in each included study, we were not able to confirm the duration-response relationship for COX inhibitors through meta-analysis. The optimal duration of COX inhibitors use for chemoprevention in patients with $\mathrm{BE}$ needs to be further explored.

Only three of the included studies offered risk estimates for dose and frequency, making it difficult to draw conclusions of dose effect and frequency effect. Tsibouris et al concluded that daily use of non-aspirin COX inhibitors reduced cancer risk in patients with BE. Vaughan et al stated that most of the COX inhibitor users took one or more doses per day during regular use. But they found no relation between frequency of NSAID use and risk of esophageal cancer $(<1$ dose per day $v s \geqslant 1$ dose per day). Kastelein et al reported dose and frequency for nsNSAIDs (acetylsalicylic acid $>325 \mathrm{mg}$ per day, carbasalate calcium $>325 \mathrm{mg}$ per day), and low-dose aspirin (acetylsalicylic acid $\leqslant 100 \mathrm{mg}$ per day, carbasalate calcium $\leqslant 100 \mathrm{mg}$ per day). We could not confirm which accurate dose was associated with protective effect through meta-analysis. Corley et al suggested in their meta-analysis that both intermittent and frequent medication use were protective, with greater protection with more frequent use in the whole population, which could help us understand this problem.

When stratified by medication type, there was also a negative association between neoplastic progression and both low-dose aspirin (37\% reduction) and non-aspirin COX inhibitors (50\% reduction). Use of non-aspirin COX inhibitors seemed to be more effective than use of low-dose aspirin. We were not able to provide separate data for selective COX-2 inhibitors and nsNSAIDs as only one study reported the information. Kastelein et al reported use of selective COX-2 inhibitors and nsNSAIDs respectively, and concluded that only use of nsNSAIDs significantly reduced risk of EAC in patients with BE. As for individual type of COX inhibitors, Tsibouris et al stated that only diclofenac daily consumption yielded a protective effect. Additional studies are necessary to determine which type of COX inhibitors is optimal.

Chemoprevention of other medications as PPIs and statins for EAC in patients with BE has also been investigated for long, and interest in combined use of COX inhibitors and these medications has arisen recently. Among the included studies, only Kastelein et al reported that use of both COX inhibitors and statins provided a stronger risk reduction than use of COX inhibitors or statins alone. We then carried out a subgroup meta-analysis to compare the estimates of COX inhibitors use adjusting for other medications to those that did not adjust. The results indicated a non-significant greater risk reduction in neoplastic progression for concomitant use of COX inhibitors and other medications (PPIs/statins).

Although some previous epidemiological studies have confirmed the chemopreventive effect of COX inhibitors for EAC in the whole population, the absence of $\mathrm{BE}$ states in cases and controls might lead to a misunderstanding of how these medications could exert their antitumour effect. Our meta-analysis was the first to evaluate whether COX inhibitors can prevent patients with BE from progressing into malignancy at great length. Besides, we synthesised data on duration response and subgroups for benefit (for example, by study design and medication type), thus providing firmer summary estimates of the association.

Beales et al (2013) performed a meta-analysis of the relationship between statins use and EAC development in BE patients. They also investigated the association between COX inhibitors and the risk of EAC in BE patients among five studies, and found that use of COX inhibitors was associated with a significantly lower incidence of $\mathrm{EAC}$ in $\mathrm{BE}$ patients $(\mathrm{OR}=0.59,95 \% \mathrm{CI}$ : 0.45-0.77), consistent with our results. However, they missed some original studies in their meta-analysis, and they did not provide any information on duration response or medication type.

Esophageal adenocarcinoma development experiences a long procedure through a multi-step sequence of metaplasia-dysplasiaadenocarcinoma. Cyclooxygenase inhibitors may act late or early in the pathway. Understanding that COX inhibitors could prevent $\mathrm{BE}$ from progressing into malignancy through our meta-analysis, we were not sure whether these medications could lower the risk of $\mathrm{BE}$ development in the first place. Anderson et al (2006) reported that use of aspirin and NSAIDs was associated with a reduced risk of $\mathrm{BE}(\mathrm{OR}=0.53,0.31-0.90$ and $\mathrm{OR}=0.40,0.19-0.81$, respectively). Omer et al (2012) also found that current aspirin users had a lower risk for developing $\mathrm{BE}$ than non-users $(\mathrm{OR}=0.56$, 0.39-0.80). However, Thrift et al (2011) demonstrated that aspirin use did not reduce the risk of $\mathrm{BE}(\mathrm{OR}=1.16,0.71-1.43)$. 
Whether COX inhibitors may act at an early stage of EAC development remains to be investigated.

Our study also had some limitations. First, all included studies were observational ones, leading to lack of random allocation of the intervention compared with RCTs. Bias due to unmeasured confounding, for example, different medications use (PPIs and statins), other health problems (angiocardiopathy) and complications, could distort the results. For instance, patients with myocardial infarction use aspirin more often, and those with complications such as reflux symptoms or upper gastrointestinal ulcers might use COX inhibitors less frequently. Besides, confounders included in adjusted estimates varied significantly among these studies. Nevertheless, confounding was unlikely to fully account for the protective association of COX inhibitors. Most studies controlled for the most influential risk factors of EAC such as age, sex, smoking, and alcohol use. Some of them further adjusted for other suspected risk factors such as use of other medications (PPIs and statins), or reflux symptoms, finding that these further adjustments did not obviously change the effect estimates. For instance, one study reported an age-, sex-, and packyears smoked-adjusted HR of 0.58 (95\% CI 0.32-1.02), and found the estimate to be significantly unchanged after further adjustment for use of statins (HR 0.62 with 95\% CI 0.34-1.10) (Kantor et al, 2012).

Second, we were not able to provide evidence for duration response. Data on detailed dose and frequency were not available in many studies, and duration for high intake of COX inhibitors was obviously different in each study, making it difficult for us to definitively draw conclusions of the accurate dose, frequency, or duration of COX inhibitors needed for a greater antitumour effect.

Third, reverse causation might exist in the included studies. To control for reverse causation in cohort studies, that is to avoid prevalent or existing cases of cancer, those patients with BE who were diagnosed as EAC during a given interval or had a follow-up of less than that given interval, ranging from 5 months to 1 year after the initial diagnosis of $\mathrm{BE}$, were excluded from each individual analysis. As for case-control studies, Tsibouris et al stated that they removed patients who started COX inhibitors in the 4 years before the diagnosis of EAC to avoid collecting data on medication consumption caused by the underlying pathology, thereby avoiding reverse causation. Thus, we were able to keep to a minimum this possibility of reverse causation.

Fourth, we failed to address how to balance the risks and benefits of COX inhibitors through meta-analysis. The wellrecognised side effects of aspirin and NSAIDs were upper gastrointestinal bleeding, peptic ulceration, and haemorrhagic stroke. Many approaches to reduce harmful effects of these medications were under investigation, including co-administration with PPIs, histamine-2 receptor antagonists, and Helicobacter pylori eradiation.

Additional well-designed epidemiological studies are needed to enhance our understanding of the relationship between COX inhibitors use and neoplastic development in patients with $\mathrm{BE}$, especially high-quality double-blinded RCTs. Heath et al (2007) has published results of an RCT on behalf of the Chemoprevention for Barrett's Esophagus Trial (CBET) Research Group. The reason why we did not bring it in our meta-analysis was that the outcomes did not meet with our inclusion criteria. Disappointingly, results of the phase II b multicentre trial indicated lack of secondary chemoprevention of celecoxib in patients with Barrett's dysplasia, which contradicted our own data. The outcomes of the RCT measured change from baseline to the active treatment period (48 weeks) in the following parameters: the proportion of biopsy samples exhibiting dysplasia, the highest grade of dysplasia, the extent of HGD/low-grade dysplasia (LGD), and the surface area affected by BE. However, our meta-analysis measured the risk of neoplastic progression in patients with $\mathrm{BE}$, which was totally different from the RCT. Moreover, the treatment duration was set as 48 weeks to at most 2 years in the RCT, which presumably is too short to reliably investigate the occurrence of EAC in most of the patients. And the number of patients (82) with BE included in the trial was rather small. All these contributed to the contradiction between our analysis and the RCT. However, the UK ASPECT trial utilising aspirin is in follow-up and should provide much more data soon.

In summary, our meta-analysis shows a negative association between COX inhibitors use and the risk of neoplastic progression in patients with BE. Both non-aspirin COX inhibitors and lowdose aspirin are associated with a reduced risk of neoplasia, and non-aspirin COX inhibitors seem to be more effective. However, COX inhibitors use seems to be independent of duration response. Future research should include more well-designed RCTs on the relationship between COX inhibitors use and the risk of EAC development in patients with BE.

\section{ACKNOWLEDGEMENTS}

This study was funded by the National Natural Science Foundation of China (Grant No. 81101814, 81272742).

\section{CONFLICT OF INTEREST}

The authors declare no conflict of interest.

\section{REFERENCES}

Abnet CC, Freedman ND, Kamangar F, Leitzmann MF, Hollenbeck AR, Schatzkin A (2009) Non-steroidal anti-inflammatory drugs and risk of gastric and oesophageal adenocarcinomas: results from a cohort study and a meta-analysis. Br J Cancer 100(3): 551-557.

Anderson LA, Johnston BT, Watson RG, Murphy SJ, Ferguson HR, Comber H, McGuigan J, Reynolds JV, Murray LJ (2006) Nonsteroidal anti-inflammatory drugs and the esophageal inflammation-metaplasiaadenocarcinoma sequence. Cancer Res 66(9): 4975-4982.

Bani-Hani KE, Bani-Hani BK, Martin IG (2005) Characteristics of patients with columnar-lined Barrett's esophagus and risk factors for progression to esophageal adenocarcinoma. World J Gastroenterol 11(43): 6807-6814.

Beales IL, Hensley A, Loke Y (2013) Reduced esophageal cancer incidence in statin users, particularly with cyclo-oxygenase inhibition. World J Gastrointest Pharmacol Ther 4(3): 69-79.

Beales IL, Vardi I, Dearman L (2012) Regular statin and aspirin use in patients with Barrett's oesophagus is associated with a reduced incidence of oesophageal adenocarcinoma. Eur J Gastroenterol Hepatol 24(8): 917-923.

Begg CB, Mazumdar M (1994) Operating characteristics of a rank correlation test for publication bias. Biometrics 50(4): 1088-1101.

Bollschweiler E, Wolfgarten E, Gutschow C, Holscher AH (2001) Demographic variations in the rising incidence of esophageal adenocarcinoma in white males. Cancer 92(3): 549-555.

Buttar NS, Wang KK, Leontovich O, Westcott JY, Pacifico RJ, Anderson MA, Krishnadath KK, Lutzke LS, Burgart LJ (2002) Chemoprevention of esophageal adenocarcinoma by COX-2 inhibitors in an animal model of Barrett's esophagus. Gastroenterology 122(4): 1101-1112.

Chalmers TC, Celano P, Sacks HS, Smith H Jr (1983) Bias in treatment assignment in controlled clinical trials. N Engl J Med 309(22): 1358-1361.

Corley DA, Kerlikowske K, Verma R, Buffler P (2003) Protective association of aspirin/NSAIDs and esophageal cancer: a systematic review and meta-analysis. Gastroenterology 124(1): 47-56.

de Jonge PJ, Steyerberg EW, Kuipers EJ, Honkoop P, Wolters LM, Kerkhof M, van Dekken H, Siersema PD (2006) Risk factors for the development of esophageal adenocarcinoma in Barrett's esophagus. Am J Gastroenterol 101(7): 1421-1429.

DerSimonian R, Laird N (1986) Meta-analysis in clinical trials. Control Clin Trials 7(3): 177-188. 
Desai TK, Krishnan K, Samala N, Singh J, Cluley J, Perla S, Howden CW (2012) The incidence of oesophageal adenocarcinoma in non-dysplastic Barrett's oesophagus: a meta-analysis. Gut 61(7): 970-976.

Fosslien E (2000) Molecular pathology of cyclooxygenase-2 in neoplasia. Ann Clin Lab Sci 30(1): 3-21.

Gaddam SYP, Wang A, Bansal A, Gupta N, Wani SB, Singh M, Singh V, Chuang KY, Boolchand V, Gavini H, Sud P, Kuczynski J, Higbee AD, Rastogi A, Mathur SC, Cash BD, Falk GW, Sampliner RE, Sharma P (2010) Predicting high-grade dysplasia (HGD) and esophageal adenocarcinoma (EAC) in patients with non-dysplastic Barrett's esophagus (BE): Results from a large, multicenter cohort study. Gastroenterology 138: S332.

Gatenby PA, Ramus JR, Caygill CP, Winslet MC, Watson A (2009) Aspirin is not chemoprotective for Barrett's adenocarcinoma of the oesophagus in multicentre cohort. Eur J Cancer Prev 18(5): 381-384.

Gerbarg ZB, Horwitz RI (1988) Resolving conflicting clinical trials: guidelines for meta-analysis. J Clin Epidemiol 41(5): 503-509.

Kendall M, Gibbons JD (1990) Rank Correlation Methods. Oxford University Press: New York.

Greenland S (1987) Quantitative methods in the review of epidemiologic literature. Epidemiol Rev 9: 1-30.

Greenland S (1994) Invited commentary: a critical look at some popular meta-analytic methods. Am J Epidemiol 140(3): 290-296.

Heath EI, Canto MI, Piantadosi S, Montgomery E, Weinstein WM, Herman JG, Dannenberg AJ, Yang VW, Shar AO, Hawk E, Forastiere AA. Chemoprevention for Barrett's Esophagus Trial Research Group (2007) Secondary chemoprevention of Barrett's esophagus with celecoxib: results of a randomized trial. J Natl Cancer Inst 99(7): 545-557.

Higgins JP, Thompson SG (2002) Quantifying heterogeneity in a meta-analysis. Stat Med 21(11): 1539-1558.

Higgins JP, Thompson SG, Deeks JJ, Altman DG (2003) Measuring inconsistency in meta-analyses. BMJ 327(7414): 557-560.

Imperiale TF, Birgisson S (1997) Somatostatin or octreotide compared with $\mathrm{H} 2$ antagonists and placebo in the management of acute nonvariceal upper gastrointestinal hemorrhage: a meta-analysis. Ann Intern Med 127(12): 1062-1071.

Jadad AR, Moore RA, Carroll D, Jenkinson C, Reynolds DJ, Gavaghan DJ, McQuay HJ (1996) Assessing the quality of reports of randomized clinical trials: is blinding necessary? Control Clin Trials 17(1): 1-12.

Kandil HM, Tanner G, Smalley W, Halter S, Radhika A, Dubois RN (2001) Cyclooxygenase-2 expression in Barrett's esophagus. Dig Dis Sci 46(4): 785-789.

Kantor ED, Onstad L, Blount PL, Reid BJ, Vaughan TL (2012) Use of statin medications and risk of esophageal adenocarcinoma in persons with Barrett's esophagus. Cancer Epidemiol Biomarkers Prev 21(3): 456-461.

Kastelein F, Spaander MC, Biermann K, Steyerberg EW, Kuipers EJ, Bruno MJ, Probar-study G (2011) Nonsteroidal anti-inflammatory drugs and statins have chemopreventative effects in patients with Barrett's esophagus. Gastroenterology 141(6): 2000-2008.

Kaur BS, Khamnehei N, Iravani M, Namburu SS, Lin O, Triadafilopoulos G (2002) Rofecoxib inhibits cyclooxygenase 2 expression and activity and reduces cell proliferation in Barrett's esophagus. Gastroenterology 123(1): 60-67.

Kim SW, Jang TJ, Jung KH, Suh JI (2007) Sulindac prevents esophageal adenocarcinomas induced by gastroduodenal reflux in rats. Yonsei Med J 48(6): 1020-1027.

Kleinbaum DG, Kupper LL, Morgenstern H (1982) Epidemiologic Research. Principles and Quantitative Methods. Van Nostrand Reinhold: New York

Molina MA, Sitja-Arnau M, Lemoine MG, Frazier ML, Sinicrope FA (1999) Increased cyclooxygenase- 2 expression in human pancreatic carcinomas and cell lines: growth inhibition by nonsteroidal anti-inflammatory drugs. Cancer Res 59(17): 4356-4362.

Morris CD, Armstrong GR, Bigley G, Green H, Attwood SE (2001) Cyclooxygenase-2 expression in the Barrett's metaplasia-dysplasiaadenocarcinoma sequence. Am J Gastroenterol 96(4): 990-996.

Nguyen DM, El-Serag HB, Henderson L, Stein D, Bhattacharyya A, Sampliner RE (2009) Medication usage and the risk of neoplasia in patients with Barrett's esophagus. Clin Gastroenterol Hepatol 7(12): 1299-1304.
Nguyen DM, Richardson P, El-Serag HB (2010) Medications (NSAIDs, statins, proton pump inhibitors) and the risk of esophageal adenocarcinoma in patients with Barrett's esophagus. Gastroenterology 138(7): 2260-2266.

Omer ZB, Ananthakrishnan AN, Nattinger KJ, Cole EB, Lin JJ, Kong CY, Hur C (2012) Aspirin protects against Barrett's esophagus in a multivariate logistic regression analysis. Clin Gastroenterol Hepatol 10(7): 722-727.

Oyama K, Fujimura T, Ninomiya I, Miyashita T, Kinami S, Fushida S, Ohta T, Koichi M (2005) A COX-2 inhibitor prevents the esophageal inflammation-metaplasia-adenocarcinoma sequence in rats. Carcinogenesis 26(3): 565-570.

Polednak AP (2003) Trends in survival for both histologic types of esophageal cancer in US surveillance, epidemiology and end results areas. Int J Cancer 105(1): 98-100.

Poole C, Greenland S (1999) Random-effects meta-analyses are not always conservative. Am J Epidemiol 150(5): 469-475.

Ronkainen J, Aro P, Storskrubb T, Johansson SE, Lind T, Bolling-Sternevald E, Vieth M, Stolte M, Talley NJ, Agreus L (2005) Prevalence of Barrett's esophagus in the general population: an endoscopic study. Gastroenterology 129(6): 1825-1831.

Schulz KF, Chalmers I, Grimes DA, Altman DG (1994) Assessing the quality of randomization from reports of controlled trials published in obstetrics and gynecology journals. JAMA 272(2): 125-128.

Schulz KF, Chalmers I, Hayes RJ, Altman DG (1995) Empirical evidence of bias. Dimensions of methodological quality associated with estimates of treatment effects in controlled trials. JAMA 273(5): 408-412.

Sharma P, Sidorenko EI (2005) Are screening and surveillance for Barrett's oesophagus really worthwhile? Gut 54(Suppl 1): i27-i32.

Shirvani VN, Ouatu-Lascar R, Kaur BS, Omary MB, Triadafilopoulos G (2000) Cyclooxygenase 2 expression in Barrett's esophagus and adenocarcinoma: Ex vivo induction by bile salts and acid exposure. Gastroenterology 118(3): 487-496.

Spechler SJ, Sharma P, Souza RF, Inadomi JM, Shaheen NJ. American Gastroenterological Association (2011) American Gastroenterological Association technical review on the management of Barrett's esophagus. Gastroenterology 140(3): e18-e52.

Stroup DF, Berlin JA, Morton SC, Olkin I, Williamson GD, Rennie D, Moher D, Becker BJ, Sipe TA, Thacker SB (2000) Meta-analysis of observational studies in epidemiology: a proposal for reporting. Meta-analysis Of Observational Studies in Epidemiology (MOOSE) group. JAMA 283(15): 2008-2012.

Sun L, Yu S (2011) Meta-analysis: non-steroidal anti-inflammatory drug use and the risk of esophageal squamous cell carcinoma. Dis Esophagus 24(8): 544-549.

Thrift AP, Pandeya N, Smith KJ, Green AC, Webb PM, Whiteman DC (2011) The use of nonsteroidal anti-inflammatory drugs and the risk of Barrett's oesophagus. Aliment Pharmacol Ther 34(10): 1235-1244.

Tsibouris P, Hendrickse MT, Isaacs PE (2004) Daily use of non-steroidal anti-inflammatory drugs is less frequent in patients with Barrett's oesophagus who develop an oesophageal adenocarcinoma. Aliment Pharmacol Ther 20(6): 645-655.

Vaughan TL, Dong LM, Blount PL, Ayub K, Odze RD, Sanchez CA, Rabinovitch PS, Reid BJ (2005) Non-steroidal anti-inflammatory drugs and risk of neoplastic progression in Barrett's oesophagus: a prospective study. Lancet Oncol 6(12): 945-952.

Vizcaino AP, Moreno V, Lambert R, Parkin DM (2002) Time trends incidence of both major histologic types of esophageal carcinomas in selected countries, 1973-1995. Int J Cancer 99(6): 860-868.

Wells GA, Shea B, O'Connell D, Peterson J, Welch V, Losos M, Tugwell P (2013) The Newcastle-Ottawa Scale (NOS) for assessing the quality of non-randomized studies in meta-analysis. http://www.ohri.ca/programs/ clinical_epidemiology/oxford.asp (Accessed 13 April 2013).

This work is published under the standard license to publish agreement. After 12 months the work will become freely available and the license terms will switch to a Creative Commons AttributionNonCommercial-Share Alike 3.0 Unported License.

Supplementary Information accompanies this paper on British Journal of Cancer website (http://www.nature.com/bjc) 


\section{APPENDIX A}

APPENDIX A MEDLINE search strategy

Key words and medical subject heading (Mesh) terms for the MEDLINE search included: ('Barrett Esophagus' [Mesh]) AND ('Anti-Inflammatory Agents, Non-Steroidal' [Mesh] OR 'nonsteroidal anti-inflammatory drugs' OR diclofenac OR indomethacin OR aspirin OR ibuprofen OR naproxen OR ketorolac OR etodolac OR sulindac OR 'COX2-inhibitors' OR celecoxib OR rofecoxib OR valdecoxib).

\section{APPENDIX B}

\section{APPENDIX B Description of quality score}

The 9-star Newcastle-Ottawa Scale (NOS) evaluates the study quality in three categories: selection, comparability, and exposure (case-control studies) or outcome (cohort studies). The NOS assigns a maximum of four questions for selection of study groups, two questions for comparability of study groups, and three questions for ascertainment of the outcome of interest. All questions have a score of 1, except for comparability, for which separate points are awarded for controlling for age and/or sex (maximum, 2 points). Nine points on the NOS reflect the highest study quality. Any discrepancies were resolved by a joint reevaluation of the original articles. 